\title{
Work - Family Conflict among Women Employees in Bangalore City
}

\author{
Dr. C. Somashekher* \\ Professor, Department of Sociology, Bangalore University, JnanaBharathi Campus, Bengaluru-56 \\ *Corresponding Author: Dr. C. Somashekher, Prof. Department of Sociology, Bangalore University, \\ Jnanabharathi Campus, Bengaluru, India
}

\begin{abstract}
This article focuses on work-family conflict related impact on women employees engaged in organized sectors of Bangalore city, Karnataka. It could be viewed as a treatise in sociology of women and work, dealing with interactions and interfacing between work, women and social structure. Since Independence, significant changes have been noticed in the labour market and employment status of women in India. Work-family conflict is an inter-role conflict situation, in a given society, which arises due to conflicting roles expected of women at work organizations and family. The objectives of the investigation are to ascertain the nature and extent of work-family conflict and to analyse its impact on social and psychological well-being of women at work. The data were collected from 280 women employees using interview schedule. The findings seem to suggest that a majority of Indian women employees experience a relatively a high degree of work-family conflict and as a result, seem to be performing under stress at work which would have its adverse effect on family life. Further, stress generating and relaxing factors have also been analysed. The introduction of pleasant and flexible work atmosphere as well as stress management programmes are strongly suggested.
\end{abstract}

Keywords: Work-Family Conflict, Psychological, Stress, Women Employees, Work Organizations.

\section{INTRODUCTION}

In the contemporary society a woman has to perform multiple roles. As an ideal woman she has to perform the duties of a faithful wife, a sacrificing mother, obedient and respectful daughter-in-law and an efficient and highly placed career woman. There are contradictory role expectations from working woman while she is at work and at home. On the professional front she is expected to be committed, dynamic, competitive, straight forward, non-sentimental and act in a "business or professional like" manner; and at home, she is expected to be sweet, soft, sensitive, adaptable, gentle, unassertive and domesticated (Misra, 1998). These contradictory expectations lead to multiple stresses and strains for women. An attempt to play one of the roles with perfection leads to an inadvertent compromise on and sacrifice of the other. Thus, a working woman finds it difficult to do justice while performing several roles simultaneously and hence seem to be facing psychological pressure; stress and healthrelated problems resulting in declining work efficiency. For the employers such role conflict means disenchantment, dissatisfaction and strained relations among women employees, their lower quality of work performance and disregard of organizational goals. Since the work organizations are the part of society, inter-role conflict will have its negative effects on the society in the form of lower standards of performance, lower quality of products and services and a growing feeling of interpersonal conflict (Abdul and Roshan, 2010). With this backdrop, the present study purports to analyse the work-family conflict, stress, anxiety among women employees and their coping strategies.

\section{REVIEW OF LITERATURE}

The phenomenon of work-family conflict has been approached from diverse applications and orientations dealing with extent, causes, consequences and remedies. Several perspectives, assumptions and presumptions relating to social and psychological implications of women taking to gainful employment for their status and role in the family and society that are in vogue have been taken up for empirical and theoretical analysis and scrutiny to gain insight into different dimensions, manifestations and ramifications of work and family conflict. Coming to conceptualization of work- 
family conflict, though there appears to be a broad consensus; the approaches vary in identifying its contextual meaning. Work and non-work life equilibrium is conceived as woman's conception and ability to manage and operate in multiple contexts: family life, personal life and professional life experiencing minimal conflict between them (Clark, 2000; Unger son \&Yeandle, 2005). The concept of work-family conflict (WFC) was elaborated in a thorough manner by Kahn and his associates (1964) employing the framework of role theory which conceives tension between work and family roles as an inter-role conflict in the context of an individual working for an organization. Worries about family interfering with work and about work interfering with family issues have been identified as the major concerns of women employees. The modern workplace with increasing proportion of women employees at different levels of responsibility with different work patterns have come to throw up issues and concerns relating to balancing the conflicting demands of work and domestic lives (Bharat, 2003; Komarraju, 1997; Rajadhyaksha\&Bhatnagar, 2000; Sekharan, 1992).

Striking a perfect balance between family life and work life, in which a woman feels that she has done adequate justice to the responsibilities appears to be quite difficult if not impossible owing to the traditional role expectations pertaining to women in all societies and more so in the case of so called orthodox communities. Focusing on the phenomenon of role conflict in the context of Indian society Desai (2003) conducted a study on work-family conflict, which is a recent phenomenon in India. He stressed the conflict between the traditional role expectations associated with women and the rational demands placed by the modern work organizations in which women are entering in greater numbers in recent years. Further, the nature of work and extent of responsibility associated with work are found to be crucial in determining the extent of role stress and work-family conflict among women employees. It appears that responsibility assigned without adequate or appropriate authority and power, which is so frequently encountered in developing economies, further adds to the conflict and stress in work organizations (Mohan and Ashok 2011).

Further, as empirically substantiated in the review, women from erstwhile traditional and orthodox societies are furthermore prone to experience work-family conflict than their counterparts from the West. It is with this review, providing the empirical and theoretical backdrop for the analysis, interpretation and attribution of the findings, an attempt is made in the paper to focus on the nature, extent, causes and consequences of work-family conflict among Indian women employees in the organized sector.

\section{OBJECTIVES}

In consonance with the scope of the study set out as stated above, following are the main objectives, the present study seeks to address itself to.

- To ascertain empirically the nature and extent of work-family conflict faced by the Indian women employees in the organized sector.

- To analyze the impact of work-family conflict on the quality of social and psychological wellbeing of Indian women employees in organized sectors.

\section{MeThodology}

Keeping in view the limitations of time and resources under which the investigator had to carry out the study, interview schedule was preferred as a tool of data collection. The instrument was so designed as to elicit the relevant data from the respondents. As many as 280 respondents were selected to collect the required data for the present study. Relevant data were gathered from a sample of women employed in various sectors of employment, such as secondary school teachers, nurses, bank employees and D group employees in the Government sector. In order to keep parity in the composition of the sample, 70 respondents were selected, by following simple random sampling method, from each of the four occupational groups for the present study.

\section{RESULTS AND DisCUSSION}

Work-family conflict refers to the incompatibility between the two domains that an individual is expected to perform or play in a given situation simultaneously in which, the performance of one role interferes with or is antagonistic to the other. In the present study work-family conflict of the respondents is classified as 'low', 'moderate', and 'high' based on the responses of the respondents to the questions specifically framed for the purpose. The respondents who feel at ease while discharging 
their responsibilities both at home and on the job are considered as experiencing low work-family conflict. The respondents who feel sometimes at ease but not all the time while discharging responsibilities both at home and job are considered those with moderate role conflict and the respondents who never feel at ease while discharging responsibilities both at home and on job are considered to be women with high work-family conflict.

Table1. Extent of Work-Family Conflict

\begin{tabular}{|l|l|c|c|}
\hline SI No & \multicolumn{1}{|c|}{ Extent of Work-Family Conflict } & Frequency & Percentage \\
\hline 1 & High Degree of Work-Family Conflict & 148 & 52.8 \\
\hline 2 & Moderate Degree of Work-Family Conflict & 94 & 33.6 \\
\hline 3 & Low Work-Family Conflict & 38 & 13.6 \\
\hline \multicolumn{2}{|c|}{ Total } & $\mathbf{2 8 0}$ & $\mathbf{1 0 0}$ \\
\hline
\end{tabular}

A majority of the respondents (52.8 percent) were of the opinion that they had to rearrange work and family obligations that conflict with one another and give them a feeling of mental stress and such stress is repeating quite often. Therefore, such respondents were categorized as those with 'high degree of work-family conflict'. The moderate degree of work-family conflict accounts for one-third (33.6 percent) of the respondents and a very small proportion (13.6 percent) of respondents were found to be relatively free from such work-family conflict. It is evident from the table-1 that the workfamily conflict is widespread and therefore it is very much necessary to identify the causal factors associated with work-family conflict and to suggest suitable remedial measures to minimize the problem. Minimization of work-family conflict results in minimization of social cost in terms of domestic violence, negligence towards children's education and health care, declining work efficiency associated with the work-family conflict.

In view of the findings based on the data presented in table-1, it may be stated that the extent of workfamily conflict experienced by Indian women employees is rather high, as assumed and also as reported by many empirical studies in the review of literature as has been widely acknowledged in literature on Indian society. Women taking to gainful employment in formal work organizations is rather recent phenomenon compared to the developed societies of the West where industrial revolution took place much earlier. Hence, the opportunities for women to seek employment in formal sectors could be traced back only to post independent era and the industrial subculture and industrialism as a way of life is yet to take deep roots in Indian society. Further, the spread of modern education, Secularism and modernization are also gaining ground but are of recent origin. These factors could be partially responsible for no change in attitude toward employment of women outside family and conception of role expectation pertaining to women. Hence, women are still mainly engaged in nurturing, cooking and other household chores, irrespective of their being employed. A situation where they are not spared from their traditional role obligations while being assigned additional professional roles outside family might be affecting their both the roles adversely leading to a sense of not being able to do justice to either of the roles on the one hand and stresses and strains both physical and mental they tend to suffer on the other could explain the fact that a majority of Indian women employees experience a strong sense of work-family conflict and another one third experiencing moderate work-family conflict with only a minuscule proportion being free from workfamily conflict

It is quite natural and logical to expect women to be taking their responsibility toward family as of prime significance particularly in the context of Indian society. It is assumed that the sense of workfamily conflict emanates from their realization that they are not devoting enough time, attention and efforts in discharging their family responsibilities owing to their being employed outside the family. The findings seem to support this assumption as those women employees who feel that their work is not affecting their family responsibilities experience substantially lower levels of work-family conflict.

Apparently, work-family conflict will create stress and many a time mental strain among the women employees. Therefore, respondents were asked the question: whether they are suffering from stress? Based on the response of the respondents the data are cross-tabulated with degree of work-family conflict and presented in Table-2. 
Table2. Extent of Work-Family Conflict and Stress

\begin{tabular}{|l|l|l|l|l|c|}
\hline \multirow{2}{*}{\multicolumn{1}{c|}{ Stress }} & \multicolumn{3}{c|}{ Extent of Work-Family Conflict } & \multicolumn{1}{c|}{$\begin{array}{c}\text { Chi-square } \\
\text { Value }\end{array}$} \\
\cline { 2 - 5 } & \multicolumn{1}{|c|}{ High } & Moderate & \multicolumn{1}{c|}{ Tow } & \multicolumn{2}{|c|}{$27.642 *$} \\
\hline Suffering from stress & $147(57.4)$ & $80(31.3)$ & $29(11.3)$ & $256(100) 91.5$ & \\
\hline Not Suffering from stress & $1(4.2)$ & $14(58.3)$ & $9(37.5)$ & $24(100) 8.5$ & \\
\hline Total & $148(52.8)$ & $94(33.6)$ & $38(13.6)$ & $280(100) 100.0$ & \\
\hline
\end{tabular}

Note: Figures in parenthesis are percentage to respective row total

* Indicate the significance at 1percent probability level

An overwhelming majority of the respondents (91.5 percent) expressed that they are suffering from the stress. However, a very small proportion ( 8.5 percent) of the respondents opined that they are free from stress. The proportion of respondents in the high degree of work-family conflict is found to be greater among the respondents who are suffering from the stress. Similarly, the proportion of respondents in the low degree of work-family conflict is highest among the respondents who are not suffering from the stress. Chi-square value has been calculated to empirically verify the hypothesis. Calculated chi-square value is found to be statistically significant at one percent probability level. Hence, it could be inferred that there is association between the degree of work-family conflict and mental stress. The respondents who are encountering high degree of work-family conflict tend to suffer from the mental stress and conversely it could also be stated that those who experience a high degree of stress are more prone to experience high degree of work-family conflict.

In the literature on work-family conflict, stress has been identified as one of the sources and manifestation of work-family conflict, leading to other health and social implications. As such, those who are suffering from stress are found to be experiencing greater sense of work-family conflict. It is rather serious observation that as many as 92 percent of the respondents are experiencing stress in their lives while striving to find a balance between work and family, and quite logically, an overwhelming majority of respondents are facing either severe or moderate work-family conflict. As such, the high incidence of work-family conflict could be attributed to the sense of stress they suffer on job and at home in striking balance between the two.

On the whole, most of the women employeessuffer from the stress and mental stress is significantly associated with the degree of work-family conflict. It is extensively reported that the stress is one of the major causes for many of health complications. Some of the stress-generating factors have been identified and respondents were asked how often each factor is generating the stress among them. Distribution of respondents according to the frequency with which each factor is being viewed as generating the stress is given in Table-3.

Table3. Stress-generating factors

\begin{tabular}{|l|l|l|l|l|l|}
\hline \multirow{2}{*}{ Stress-Generating factors } & \multicolumn{3}{|l|}{ Generate the Stress } & \multirow{2}{*}{ Total } & $\begin{array}{l}\text { Average } \\
\text { Score }\end{array}$ \\
\cline { 2 - 6 } & Always (1)\# & Sometimes (0.5)\# & Never (0)\# & & $3(01.1)$ \\
\hline Heavy Work Load & $56(20.0)$ & $221(78.9)$ & $280(100)$ & 0.59 \\
\hline Negative Attitudes of Higher Officers & $9(3.2)$ & $207(73.9)$ & $64(22.9)$ & $280(100)$ & 0.40 \\
\hline Financial Problems & $26(9.3)$ & $176(62.9)$ & $78(27.8)$ & $280(100)$ & 0.41 \\
\hline Unfavourable Attitude of Husband & $13(4.7)$ & $84(30.0)$ & $183(65.3)$ & $280(100)$ & 0.20 \\
\hline Failures in Children Care & $37(18.9)$ & $99(50.5)$ & $60(30.6)$ & $196(100)$ & 0.44 \\
\hline Dual/ Multiple Roles & $211(75.4)$ & $55(19.6)$ & $14(05.0)$ & $280(100)$ & 0.85 \\
\hline
\end{tabular}

Note: Figures in Parenthesis are percentage to respective total

\section{\# Score to the respective intensity of stress generation}

It is clear from the above table that more than three-fourths of the respondents ( 78.9 percent) expressed that they sometimes experience the stress due to heavy workload. However, one-fifth (20 percent) of the respondents answered that the heavy workload always generates the stress in their mind. Only three of the respondents reported that they never experience the stress due to heavy work load. The table is self-explanatory. In order to ascertain the factor which is more frequently generating the stress, suitable scoring technique has been adopted. In this scoring technique, with respect to each factor, score 1 is assigned to a respondent if it is always generating the stress; and the score 0.5 is assigned if it is generating the stress sometimes; and the score 0 is assigned if it never generates the stress. With respect to each factor the score of each respondent was summed up and the score has 
been divided by the number of respondents and thus the average score has been computed. If the average scores pertaining to any particular factor are summed up, it does mean that this particular factor is generating the stress always to all the respondents. The average score is zero (0) means that particular factor is never generating the stress to anybody. Thus, the average score ranges between 0 and 1.

The average score is highest for the dual/multiple roles (0.85). Three-fourths (75.4 percent) of the respondents reported that they are experiencing the stress always due to multiple roles and about onefifth (19.6 percent) of respondents reported that sometimes they are experiencing the stress due to this factor. Thus, it could be inferred that multiple role is the most significant factor which generates the stress. Heavy work load is another factor which secures the second highest average score. Further, failure in child care is the factor which generates the third highest average score.

Such a widely prevailing stress, as assumed could be owing to several as pacts of their professional and family life. Out of the six possible reasons for the stress they experience, quite logically, the requirement of performing multiple roles, in the family and on job appear to be the most significant as it could be understood as the source of factors leading to stress, like heavy work load and a sense of not being able to take good care of their children. It may be attributed to the finite capacity of an individual to be able to do justice to multiple roles simultaneously. However, it is heartening to note that the women employeesare not so much subject to the negative attitudes of their superiors in the work organizations and even more heartening is the fact that nearly two thirds of the respondents do not suffer unfavourable attitude of their husbands, which could be the source of stress in their family and work life.

Stress is considered one of the most major causes for the ill-health. Women have to find a solution which could give her relaxation from the stress. Some of the factors which could give relaxation from the stress have been identified and the respondents were asked about how frequently they could get relaxation from each factor. Distribution of respondents according to the frequency with which they could get relaxation from each factor is presented in Table-4.

Table 4.Factors Help in Relaxation from Stress

\begin{tabular}{|c|c|c|c|c|c|}
\hline \multirow{2}{*}{ Relaxation Factors } & \multicolumn{3}{|c|}{ Get Relaxation from Stress } & \multirow{2}{*}{ Total } & \multirow{2}{*}{$\begin{array}{l}\text { Average } \\
\text { Score }\end{array}$} \\
\hline & Always (1)\# & Sometimes (0.5)\# & Never (0)\# & & \\
\hline Spending Time With Family Members & $270(96.4)$ & $10(3.6)$ & $0(0.0)$ & $280(100)$ & 0.98 \\
\hline Spending Time With Friends & $82(29.3)$ & $190(67.8)$ & $8(2.9)$ & $280(100)$ & 0.63 \\
\hline Spending Time With Colleagues & $66(23.6)$ & 202(72.1) & $12(4.3)$ & $280(100)$ & 0.60 \\
\hline By Watching TV/ Movies & $42(15.0)$ & 191(68.2) & $47(16.8)$ & $280(100)$ & 0.49 \\
\hline By Listing Music & 101(36.1) & $156(55.7)$ & $23(8.2)$ & $280(100)$ & 0.64 \\
\hline Meditation/Prayer & 261(93.2) & $11(3.9)$ & $8(2.9)$ & $280(100)$ & 0.95 \\
\hline Loneliness & $53(18.9)$ & 53(18.9) & $174(62.2)$ & $280(100)$ & 0.28 \\
\hline Shopping & $52(18.6)$ & $134(47.8)$ & $94(33.6)$ & $280(100)$ & 0.43 \\
\hline Pilgrimage & 256(91.4) & $18(6.4)$ & $6(2.2)$ & $280(100)$ & 0.95 \\
\hline
\end{tabular}

Note: Figures in Parenthesis are percentage to respective total

\section{\# Score to the respective intensity of relaxation from stress}

In order to ascertain the factors which, give relaxation more frequently, a scoring technique has been adopted. In this scoring technique, with respect to each factor, score 1 is assigned to a respondent if it always gives relaxation from the stress; and 0.5 is assigned if it is relaxing from the stress occasionally; and the score 0 is assigned if it never helps in relaxing from the stress. With respect to each factor the score of each respondent was summed and the score has been divided by the number of respondents and thus the average score has been computed. If the average score pertaining to any particular factor is 1 , it means that this particular factor is relaxing from the stress always to all the respondents. The average score zero (0) means that the particular factor is of no help in relaxing from the stress to anybody. Thus, the average score ranges between 0 and 1.

The average score is found to be highest (0.98) for the factor spending time with family members. An overwhelming majority (96.4 percent) of the respondents expressed that they could always get relaxation from the stress by spending time with the family members. Remaining respondents 
reported that they could sometimes get relaxation from stress by spending time with the family members. Thus, family is a unit of the society which has a power to give pleasure to a family member and it is a source of mental peace, support and pleasure. Meditation/prayers and pilgrimage are the two separate factors which have secured the second highest average score. More than 90 percent of the women employees reported that they always get relaxation from the stress by meditating or praying.

It is a known fact that women employees face many challenges and problems for just being women. Gender bias and prejudice create an obstacle at every stage in working environment. The age-old belief of male superiority over women creates several hurdles for women at their place of work. The general belief is that the women are capable of less work and less efficient than men but in the modern society women are skilled to enter all types of occupations and professions. By all these views an attempt has been made in this research study to analyse the women employees' role in the organized sectors.

It may be noted that for women employees the main source of stress and sense of work-family conflict is owing to their not being able to discharge their family responsibility as it is a general observation that a woman could sacrifice her job for the family but may not be agreeable to sacrifice family for the sake of job. Thus, spending time with family members as the most effective way of relaxing from stress could be attributed to this sense of caring for and being with family as much as they can.

Meditation and prayers as distressing strategies appear to be. Becoming popular these days as benefits of yoga are extensively being propagated those days, followed by visit to the holy places or pilgrimage. Further, in the life of a working woman colleagues matter next only to the family members and same is the case with friends with whom they might have spent most gratifying and enjoyable time during their school or college days. Hence, it appears rather logical for them to feel relaxed from stress, when they spend time with their colleagues and friends. However, watching TV appears to be least preferred actively for relaxation to overcome stress which could be attributed to the time constraint women employees tend to face after having spent long hours on work, attending to domestic chores and spending time on social life.

\section{CONCLUSiON}

The data obtained and analysed for the present study suggest that more than one-half of the respondents are found to be experiencing high degree of work-family conflict. It is essential to undertake more structured and focused research not only to measure conflict, but also to assess the nature of the process of and reasons for work-family conflict particularly from the point of view of the structure and functioning of work organizations, the nature of job requirements as well as the familial situations in which the women employees live and operate. Stress is the major cause of worry in the lives of women employees. Stress in the workplace is increasingly a critical problem for workers, employers and societies that tends have negative implications on the family front as well. Researchers who have studied stress for women at work place have come to acknowledge direct and indirect costs of stress for women in employment in terms of physical, social and psychological wellbeing. Hence, it is need of the hour to create a pleasant and flexible work atmosphere as well as to organize stress management programmes in work organizations in the near future. The people of India have been experiencing sea change in the social norms and values, owing to several forces of social change and economic development and despite patriarchy, women employees have been acquiring new values and elevate their status and importance in the family due to her earning potentiality by choosing a career and gaining power of decision-making. Work-family conflicts, stress and strain among the women employees affect their career, goals and their lives and the lives of the other members in the family. A working woman who views career as extremely important could take her responsibilities toward family less seriously as they could interfere with her career aspirations and prospects. But the study reveals that Indian women employees still consider and take their family obligations quite seriously as compared to their professional responsibilities and in doing so stretch themselves far beyond their limits of endurance leading to a severe sense of stress and high degree of work-family conflict. This situation warrants a considerate approach and orientation toward women employees both by the family and society on the one hand and the employers and the work organizations on the other. 


\section{REFERENCES}

[1] Abdul, G and Roshan, A (2010). Conflicting Worlds of Women: Findings of an Exploratory Study. Indian Journal of Industrial Relations, Vol. 46 (1).

[2] Barling, J., Macewen, K. E., Kelloway, K. \&Higginbottom, S. F. (1994). Predictors and Outcomes of Elder-Care-Based Inter-Role Conflict', Psychology and Aging, vol. 9, no.3, pp. 391-397

[3] Clark SC (2000). Work/Family Border Theory: A New Theory of Work/Family Balance. Human Relations 53(6): 747-770.

[4] Frone, M. R., Russel, M. \& Cooper, M. L. (1992). Antecedents and Outcomes of Work-Family Conflict: Testing a model of the work-family interface'. Journal of Applied Psychology, vol. 77, pp. 65-78

[5] Goode, W.J. (1960). A theory of role strain. American Sociological Review, 25, 483-496.

[6] Greenhaus, J. H. \&Beutell, N. J. (1985). 'Sources of Conflict Between Work and Family Roles'. Academy of Management Review, vol. 10, no. 1, pp. 76-88.

[7] Judge, T.A., Boudreau, J.W., \&Bretz, R.D. (1994). Job and life attitudes of male executives.

[8] Kahn, R.L, Wolfe, D.M., Quinn, R., Snoek, J.D., \& Rosenthal, R.A., (1964). Organizational Stress. New York: Wiley.

[9] Komarraju M. 1997. "The work-family interface in India", in S. Parasuraman and J. H. Greenhaus Eds., Integrating work and family, Challenges for a changing world pp. 104-114. Westport, CT, Quorum Books.

[10] Misra, Pushpa 1998. The Parental Leave Directive: Towards a Family-Friendly Social Europe. European Journal of Industrial Relations, 8 (2): pp157-72.

[11] Moen, P., \& Yu, Y. (2000). Effective work/life strategies: Working couples, work conditions, gender and life quality. Social Problems, 47, 291-326.

[12] Mohan, N., \& Ashok, J., (2011). Stress and Depression Experienced by Women Software Professionals in Bangalore, Karnataka, Global Journal of management and Business

[13] Netemeyer, R.G., Boles, J.S., \&McMurrian, R. (1996). Development and validation of work-family conflict and family-work conflict scales. Journal of Applied Psychology, 81(4), 400-410.

[14] Rajadhyaksha U. and Bhatnagar, D. 2000. "Life role salience, A study of dual career couples in the Indian context". Human Relations, Vol.53, pp.489-511.

[15] Sekaran U. 1992. "Middle-class dual-earner families and their support systems in urban India", in S. Lewis, D. N. Izraeli, and H. Hootsmans ed., Dual-earner families, International perspectives. pp. 46-61. Newbury Park, CA, Sage.

[16] Unger son C, Yeandle, S (2005). Care Workers and Work-Life Balance: The Example of Domiciliary Care workers. In: Hounston DM, ed. Work-Life Balance in the 21st Century, pp. 246-262. Hampshire, Palgrave Macmillan.

[17] Voydanoff, P. (2004). Implications of work and community demands and resources for work-to-family conflict and facilitation. Journal of Occupational Health Psychology, 9(4), 275-285.

Citation: Dr. C. Somashekher. "Work - Family Conflict among Women Employees in Bangalore City." International Journal of Research in Sociology and Anthropology (IJRSA), vol 4, no. 1, 2018, pp. 1-7. doi:http://dx.doi.org/10.20431/2454-8677.0401001.

Copyright: ( $) 2018$ Authors. This is an open-access article distributed under the terms of the Creative Commons Attribution License, which permits unrestricted use, distribution, and reproduction in any medium, provided the original author and source are credited. 